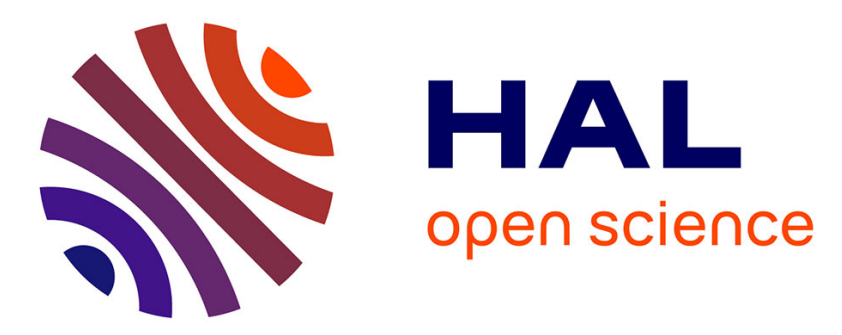

\title{
Influence of heterogeneities on mechanical properties: Virtual material concept
}

\author{
Roman Zhuravlev, Sandra Guerard, Catherine Froustey
}

\section{To cite this version:}

Roman Zhuravlev, Sandra Guerard, Catherine Froustey. Influence of heterogeneities on mechanical properties: Virtual material concept. Construction and Building Materials, 2019, 196, pp.82-94. 10.1016/j.conbuildmat.2018.11.095 . hal-02308608

\section{HAL Id: hal-02308608 \\ https://hal.science/hal-02308608}

Submitted on 5 Feb 2020

HAL is a multi-disciplinary open access archive for the deposit and dissemination of scientific research documents, whether they are published or not. The documents may come from teaching and research institutions in France or abroad, or from public or private research centers.
L'archive ouverte pluridisciplinaire $\mathbf{H A L}$, est destinée au dépôt et à la diffusion de documents scientifiques de niveau recherche, publiés ou non, émanant des établissements d'enseignement et de recherche français ou étrangers, des laboratoires publics ou privés. 


\title{
Influence of heterogeneities on mechanical properties: Virtual material concept
}

\author{
R. Zhuravlev ${ }^{\mathrm{a}}$, S. Guérard ${ }^{\mathrm{a}, *}$, C. Froustey ${ }^{\mathrm{b}}$ \\ ${ }^{a}$ Arts et Métiers ParisTech, Institut de Mécanique et d'Ingénierie de Bordeaux, UMR CNRS 5295, Esplanade des Arts et Métiers, Talence, France \\ ${ }^{\mathrm{b}}$ Université de Bordeaux, Institut de Mécanique et d'Ingénierie de Bordeaux, UMR CNRS 5295, Esplanade des Arts et Métiers, Talence, France
}

\section{H I G H L I G H T S}

- VM approach allows the study of theoretical case in connection with the real experiment.

- Analytical approach to study isotropy of heterogeneous specimens was suggested.

- The specimens behaviour significantly depends on the volume fraction of inclusions.

- The specimens behaviour weakly depends on the size of inclusions.

- VM approach can be used in tasks of homogenization and numerical optimization.

\begin{abstract}
A B S T R A C T
The present article is connected to the study of a bituminous mixture (BM) material, used on modern railway track as sub-ballast layer. Influence of size and volume fraction of rigid monodisperse spherical inclusions, randomly packed into a hyperelastic matrix, on the mechanical behavior of an obtained composite structure was investigated using "Virtual Material" approach. 3D geometry of inclusions was defined and used for 3D printing and 3D finite element modeling. This approach allows a numerical study of a theoretical case without losing connection with real experiment (by means of direct geometrical correspondence). Parameters of 7 specimens were chosen in accordance with a Doehlert experimental design. Analysis performed on the basis of the "response surfaces" approach has shown that mechanical parameters of studied specimens have a strong dependence on the value of inclusions volume fraction and almost no dependence on the value of the size of inclusions. Stress/strain concentrations were analyzed using FE method in order to find and to visualize load-bearing chains going through the matrix. It was found that Von Mises stress in load-bearing chains is almost 8 times higher than the average in the matrix.
\end{abstract}

\section{Introduction}

The modern railway track is a complex multilayer structure, designed to sustain the dynamic load of passing trains while improving the resistance of railway bed to external factors and increasing its lifetime at a wide range of working conditions. Classical sub-ballast layer, constituted of a well-crushed and compacted stones, was initially designed to sustain only compressive loads in a vertical direction. The lack of binding between particles in such a structure as well as the constant influence of precipitation, temperature changes and cyclic loading inevitably lead to degradation of the layer and accumulation of a vertical deformation. Moreover, recent in-situ measurements have shown that tensile deformation of the sub-ballast layer, caused by a passing train, in longitudinal and transversal directions cannot be neglected [1]. It was found that using a bituminous mixture (BM) layer instead of a compacted crushed-stone layer improves the mechanical behavior of railway track and leads to a significant decrease of maintenance operations [1]. Viscoelastic properties of such a material allow damping noise and vibration while rigid particles, bound together by asphalt, form a stable support for upper layers. Despite obvious advantages of such approach, there is still not enough experience in this field: experimental investigations and modeling of BM are commonly based on its macroscopic behavior, which depends directly on characteristics of the material composition (mechanical properties of constituent materials and their volume/mass fractions). A BM classically consists of compacted mineral aggregates of different size 
( $~ 80-85 \%$ of the total volume and $90-96 \%$ of the total mass) incorporated into the bitumen matrix ( $\sim 10-12 \%$ of the total volume and $4-10 \%$ of the total mass) with a presence of a low quantity of air bubbles ( $\sim 3-5 \%$ of the total volume).

In engineering applications, it is common to focus experimental studies mainly on macroscopic parameters (such as dynamic modulus, fatigue resistance, etc.) of BMs' mechanical behavior [2]. It can be also noted that constitutive models of BM are usually proposed on the basis of the macroscopic behavior of the material [3-5]. However, a full investigation of heterogeneous materials cannot be carried out apart from the mesoscopic approach. Analysis of the material behavior on meso-scale allows to study precisely the influence of parameters of internal structure on the macroscopic behavior [6,7]. Experimental techniques available for such studies, however, are very limited to a few methods of nondestructive testing (e.g. X-ray tomography) and often apply restrictions on specimen's size, shape and conditions of the experiment.

Significant progress in computational capacities allows the use of numerical approaches, such as finite element method (FEM) and less often discrete element method (DEM), to study internal mechanics of composite materials. Works concerning numerical modeling of composite materials on meso-scale can be divided into two groups. Works from the first group are devoted to study of a theoretical representative volume element (RVE) using 2D [8,9] or 3D [9-13] approaches. These works usually lack connection with real cases and provide more theoretical and qualitative results. In the second group, authors have chosen to work with numerical RVE (2D and 3D) developed from real architecture using X-ray tomography or optical surface scanning techniques [14-19]. These works represent the physics and properties of the material, are sufficient for performing numerical analysis, but are devoted to study one specific given case.

The present study investigates a new "Virtual Material" (VM) concept, based on inclusions embedded in matrix made from additive manufacturing process. It allows keeping the connection between numerical and real specimens without losing generality and studying the influence of heterogeneity of a two-component material on its mechanical behavior.

\section{Virtual material concept}

Main ideas of VM concept can be postulated as follows: 1) development of an artificially heterogeneous material with controlled level of heterogeneity by parameters chosen a priori; 2) direct geometrical correspondence between numerical and real specimens in order to exclude influence of the inclusions location and distribution in the matrix; 3 ) material models for the numerical specimen are based on the mechanical behavior of materials constituting the real specimen.

The question of computational efficiency implies a number of assumptions to be taken when the numerical approach on mesoscale is considered. To reduce the number of input parameters, the "Virtual Material" was developed with the following assumptions: 1 ) even if the influence of shape is expected [20], inclusions are spherical and monodisperse; 2) location of inclusions is random; 3 ) inclusions are rigid (non-deformable) compared to the matrix; 4) the matrix has a non-linear elastic behavior. The size (diameter $D$ ) and the volume fraction $\left(V_{f r}\right)$ of inclusions were chosen as input parameters for investigation of the mechanical behavior of VM. The study was carried out using 3D approach, which allows to describe out-of-plane contacts and interlock effects limited in 2D approach $[9,15,18]$.

An experimental investigation at quasi-static strain rate was considered for this type of structure since both constitutive materials have a strain rate independent behavior.

\subsection{General approach}

Schematically, the process of development of numerical VM specimen for a given \{diameter; volume fraction\} pair can be explained as follows: (Step 1) forming an inclusions skeleton by random packing of inclusions inside a cubic volume of edge L conserving a minimum distance between particles (Section 2.3.1); (Step 2) locating the inclusions skeleton in the center of a cubic matrix of edge equal to $\mathrm{L}+\Delta \mathrm{L}$ (secures inclusions inside the specimen and prevents them from falling out); (Step 3) importing of the numerical specimen to a finite element software and meshing (Section 3.2.2).

Manufacturing of real specimens was based on the numerical geometry obtained after Step 2 and required additional steps: (Step 3b) Arrangement of links, which connect inclusions between each other (Section 2.3.2) and allows to maintain inclusions in their original locations; (Step 4b) 3D printing of obtained inclusions skeletons and (Step 5b) molding of the printed geometries into silicon matrix (Section 2.4).

\subsection{Parameters of VM specimens}

The ratio between specimen and inclusions characteristic sizes $L / D$ has a direct influence on both numerical complexity of the model and its prediction capabilities [21-25]. The range of values for the inclusions size parameter ( $D=8-12 \mathrm{~mm}$ ) was chosen in accordance with the grading curve of a BM material used on real railway tracks [1], while the specimen size was chosen to keep the ratio $L / D$ in a range of $3.6-6.6$ as proposed in [22]: here $L=60 \mathrm{~mm}$ and $\Delta L=10 \mathrm{~mm}$ were taken.

The range of volume fractions (0-30\%) was taken keeping in mind the maximum values for this parameter obtained in literature for monodisperse spherical inclusions during random packing [24].

Finally, the following pairs of inclusions parameters "volume fraction-diameter" $\left(V_{f r}[\%] ; D[\mathrm{~mm}]\right)$ were chosen in accordance with a Doehlert experimental design [26]: $(0 ; 10),(7.5 ; 8),(7.5$; $12),(15 ; 10),(22.5 ; 8),(22.5 ; 12)$ and $(30 ; 10)$ (see Fig. 1$)$. In the following text, a particular specimen will be denoted by the form Vxx-Dxx (i.e. V15-D10 refers to the specimen with $10 \mathrm{~mm}$ diameter inclusions occupying $15 \%$ of $60 \times 60 \times 60 \mathrm{~mm}^{3}$ volume). The use of experimental design allows identification of input factors, which have the most significant influence on resulting value of the studied output variable. Additionally, a qualitative study of variation of the response variable, using polynomial interpolation of experimental data can be carried out constructing "response surfaces" (see Section 3.3.2).

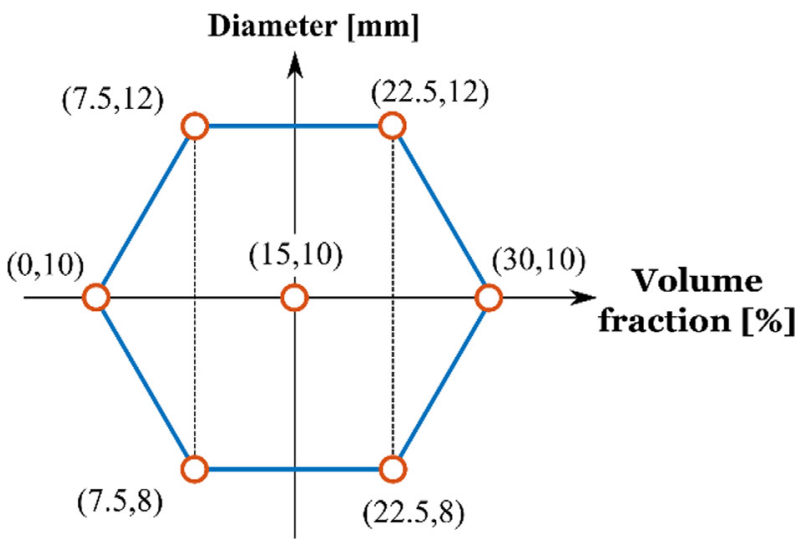

Fig. 1. Specimens parameters on the scale of the Doehlert diagram $\left(V_{f r}[\%] ; D\right.$ $[\mathrm{mm}])$. 


\subsection{Numerical development of an inclusion skeleton}

\subsubsection{Packing of inclusions}

Spherical inclusions were randomly packed [27] into a cubic volume with $L=60 \mathrm{~mm}$ using open source software GranOO [28]. GranOO software tries to pack the predefined number of inclusions while avoiding mutual intersection and intersection with borders of the cubic specimen.

An additional constraint of a minimum distance $a$ between inclusions was applied during packing. First of all, this allows to preserve the connection with a real case of the study, when particles are separated by matrix material $[12,13,29]$. Additionally, an excessive mesh refinement (which can greatly affect the computational time) and the presence of distorted elements can be avoided $[21,22,30]$. A minimum distance of $1 \mathrm{~mm}$ (16-25\% of inclusions' radius) between any two inclusions and $0.5 \mathrm{~mm}$ between any inclusion and a border of the cube was guaranteed in the present study. Target and resulted volume fractions (defined as $V_{f r}=\frac{4 \pi R^{3}}{3} \cdot N_{\text {inclusions }} / L^{3}$ with $R$ corresponding to the radius of inclusions and $N_{\text {inclusions }}$ to the total number of inclusions in the specimen), as well as a number of inclusions packed during the procedure described above, are presented in Table 1. An average difference between target and resulted volume fraction is found to be less than $0.5 \%$.

\subsubsection{Arrangement of links}

Presence of links between inclusions can naturally influence the mechanical behavior of the final specimen. Thus, number and length of links initially obtained using Delaunay triangulation were optimized. First of all, links intersecting more than one inclusion were deleted. Secondly, the number of links was optimized in such a way that each inclusion is connected to not more than 4 links and not less than 3 links.

\subsubsection{Analytical study of developed inclusion structures}

A random position of inclusions, as well as presence of rigid links, can influence the specimen's isotropy and homogeneity. Isotropy is a very important characteristic of composite materials, which can influence strategy for studying and modeling of such materials. The internal structure of developed VM specimens was analyzed analytically in order to study homogeneity of inclusions distribution and estimate volume fraction and orientation of rigid links.

\section{a) Inclusions centroid and moment of inertia}

Isotropy of inclusions distribution was analyzed following the procedure proposed by Segurado and Llorca [30]: 1) computing of the particles centroid coordinates, and 2) computing its moment of inertia in relation to the three perpendicular axes originated at the center of the specimen. Results of these calculations are plotted in Fig. 2a and b versus the total inclusions surface (data obtained for different specimens with the same value of $V_{f r}$ can thus be distinguished). Coordinates of centroids were compared to the central line of a cube (Fig. 2a). The moment of inertia of each inclusions arrangement was compared with the moment of inertia of an equivalent homogeneous cubic specimen, whose mass is equal to the mass of all inclusions $\left(M_{\text {cube }}=V_{f r} L^{3} \rho\right.$, where $\rho$ is the density of inclusions taken as $1 \mathrm{~g} / \mathrm{cm} 3$ for simplicity).

\section{b) Total volume fraction of links. Links orientation}

Links can be considered as randomly oriented rigid fillers inside the matrix. Volume fraction, as well as the orientation of links, can be analyzed in order to estimate their contribution to the mechanical behavior of VM specimens. The volume fractions of links (1 mm in diameter, see Section 2.4.1) calculated for different specimens is presented in Fig. 3a. It is seen that this value is negligibly small $(0.34 \%$ at maximum) compared with the volume fraction of inclusions.

Rigid fibres oriented with the direction of load can sufficiently increase the rigidity of a composite material. By analogy, an orientation of links relative to the three directions of the cubic specimen can influence isotropy of its behavior. It was assumed that the mechanical response of a VM specimen is influenced mostly by links inclined by less than $45^{\circ}$ towards main axes. A percentage of links oriented in each of three directions of the cubic specimen is compared in Fig. 3b. It can be seen that the difference between directions does not exceed $10 \%$ from an average for the most of the studied structures.

Summarizing the above discussion, small volume fraction and absence of the primary orientation allow expecting a negligible influence of links presence on the mechanical behavior of studied specimens, especially by the means of its isotropy.

\subsection{Manufacturing of a real specimen}

\subsection{1. $3 D$ printing of the inclusions skeleton}

An example of the structure obtained after all described manipulations is presented in Fig. 4. Inclusions skeletons were completed by four supporting legs, which help locating it in the center of the $\mathrm{L}+\Delta \mathrm{L}=70 \mathrm{~mm}$ cubic box (Fig. 4).

Inclusions skeletons were manufactured by a 3D professional printer using ABS plastic material (acrylonitrile butadiene styrene terpolymer with density in a range of $0.9-1.1 \mathrm{~g} / \mathrm{cm} 3$ and Young modulus between 1700 and $2600 \mathrm{MPa}$ ) with a spatial resolution of $0.25 \mathrm{~mm}$. Each structure was printed using two materials: space not occupied by inclusions and links was filled with supporting material, which can be chemically removed afterwards. An example of a printed inclusions skeleton (V22.5-D12) is presented in Fig. 4b.

Geometries produced by 3D printing technique have a nonsmooth, stair-like surface with a step height equal to the printer resolution (Fig. 4c). Such surface of inclusions can influence the behavior of VM specimens, and more precisely, the contact behavior between inclusions and matrix. In order to preserve conformity, all specimens were printed in the X-direction.

The choice of links diameter was mostly based on the stability of the printed structure and was defined by printing a small portion of the final geometry. It was found that links with a diameter of $1 \mathrm{~mm}$ provide sufficient rigidity for the structure without an excessive increase in volume fraction $(0.13-0.34 \%$, see Section 2.3.3b).

Printing and chemical leaching of each specimen took approximately $12-24 \mathrm{~h}$ depending on specimen complexity.

Table 1

Parameters of inclusions skeletons obtained after packing procedure.

\begin{tabular}{|c|c|c|c|c|c|c|c|}
\hline & V00-D10 & V7.5-D8 & V7.5-D12 & V15-D10 & V22.5-D8 & V22.5-D12 & V30-D10 \\
\hline Target $V_{f r}[\%]$ & 0.0 & 7.5 & 7.5 & 15 & 22.5 & 22.5 & 30 \\
\hline Resulted $V_{f r}[\%]$ & 0.0 & 7.45 & 7.54 & 15.03 & 22.46 & 22.62 & 30.06 \\
\hline Number of inclusions & 0 & 60 & 18 & 62 & 181 & 54 & 124 \\
\hline
\end{tabular}



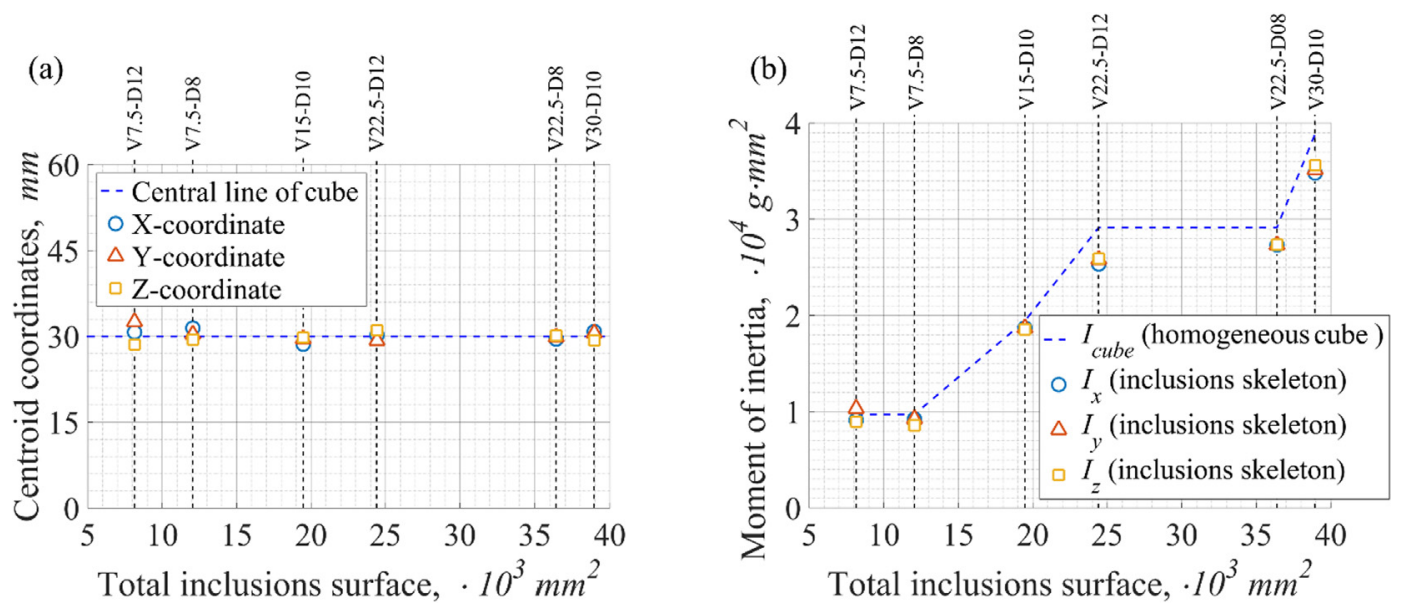

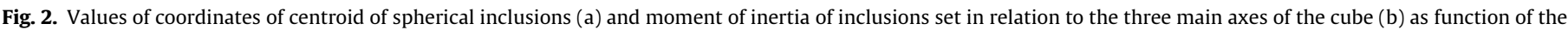

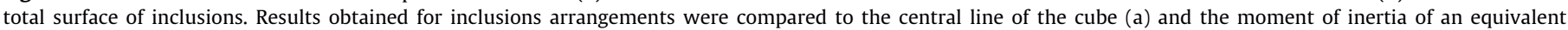
homogeneous cube (b).


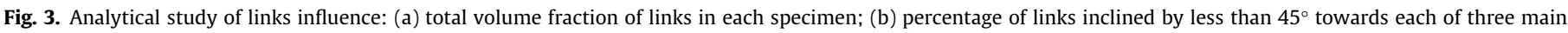
directions.

\subsubsection{Molding inclusions skeletons into silicone matrix}

Inclusions skeletons were molded into a $70 \mathrm{~mm}$ side cubic matrix using silicon material in the Z-direction (Fig. 4d). The silicone is supplied as a liquid viscous substance, which solidifies after mixing with a hardener component in the proportion of 100-5 ( $100 \mathrm{~g}$ of a silicone to $5 \mathrm{ml}$ of a hardener). Silicone and hardener components were taken with a precision of $0.1 \mathrm{~g}$ and $0.1 \mathrm{ml}$ respectively.

Liquide silicone can contain a certain quantity of air bubbles (especially after mixing with the hardener), which can naturally decrease the rigidity of the dried material. Thus, degassing of the silicone mold is a very important step in the specimen preparation process which was performed for each silicone mold using a vacuum chamber.

Finally, drying takes 1-2 days depending on the matrix volume fraction. Plastic inclusions $\left(E_{A B S}=2150 \mathrm{MPa}\right)$ can be considered as rigid compared to the silicone matrix ( $E_{\text {silicone }} \sim 0.5 \mathrm{MPa}$ ). It must be also mentioned that preliminary tests have shown no adhesion between dried silicone and ABS plastic (used for 3D printing of inclusions skeletons).

\section{Macroscopic response of "virtual material}

In accordance with the definition of "Virtual Material", both experimental and numerical approaches were used in the present study. Macroscopic response of VM subjected to compressive load was analyzed mainly by means of two parameters of its observed behavior: 1) maximum force parameter $\left(F_{\max }\right)$ and 2$)$ fraction of dissipated energy from the total accumulated energy $\left(E_{\%}\right)$.

The value of $F_{\max }$ corresponds to the value of force at the maximum level of applied compressive displacement and allows to compare the stiffness regardless the nonlinearity of the specimen response.

Parameter $E_{\%}$ corresponds to the capability of VM to dissipate energy and can be defined as follows:

$E_{\%}=\frac{\text { Energy dissipated }}{\text { Energy accumulated }} \cdot 100 \%$

where Energy accumulated is the energy accumulated in the material during loading and Energydissipated is the energy dissipated by material for one loading-unloading cycle.

\subsection{Experimental approach}

\subsubsection{Experimental method}

VM specimens were subjected to quasi-static compression load with displacement control, using an electromechanical testing machine, instrumented with a $50 \mathrm{kN}$ load cell and stainless steel compression plates. No glue or lubricant was applied between specimens and plates' surfaces to limit frictional sliding. Before the experiment, all specimens were kept in a climate chamber at $23^{\circ} \mathrm{C}$ for $24 \mathrm{~h}$ in order to eliminate the influence of the tempera- 

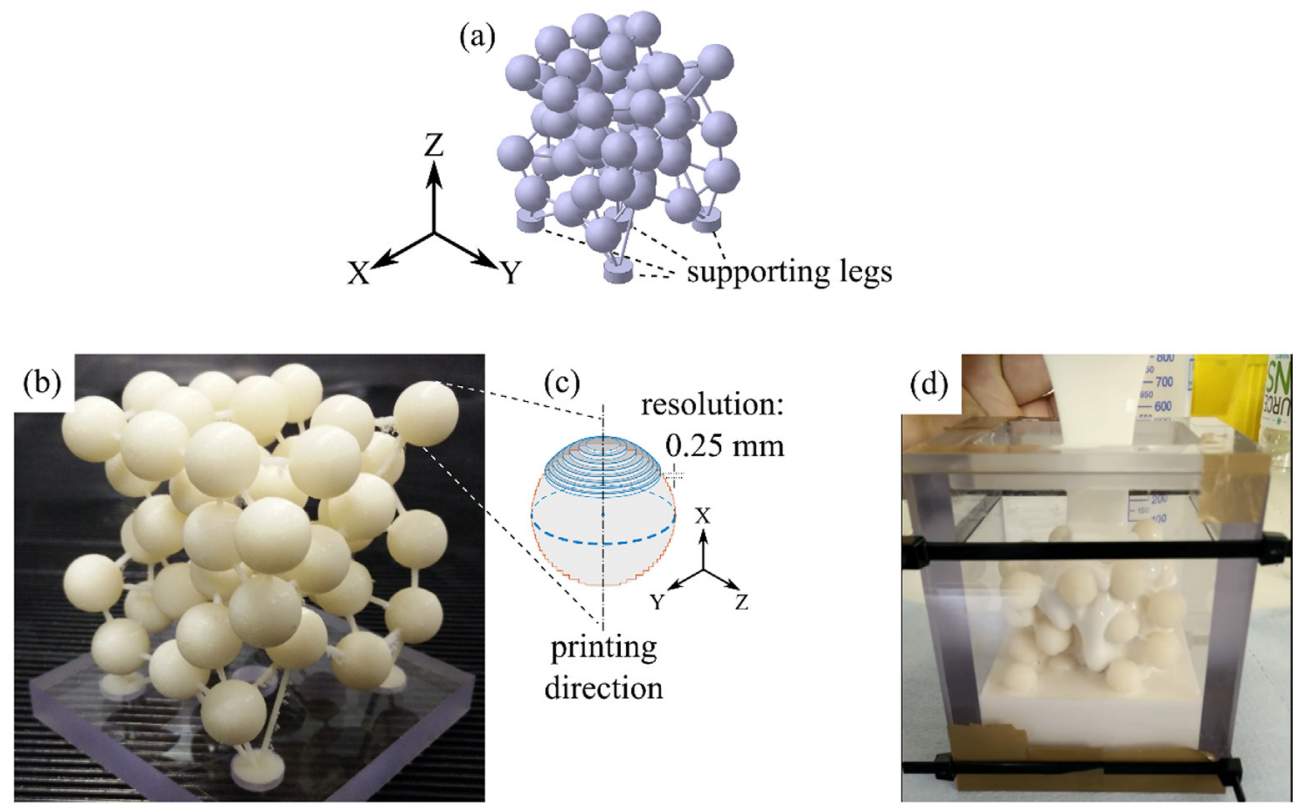

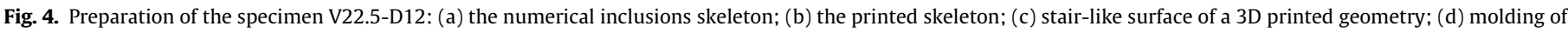
the skeleton into the silicone matrix.

ture variation. In order to decrease the influence of links on the mechanical behavior, all specimens were preliminarily subjected to cyclic loading with an amplitude of $15 \mathrm{~mm}$ in each of primary directions ( $\mathrm{X}, \mathrm{Y}$ and $\mathrm{Z}$ ). It is assumed that the majority of links was broken during this pre-cycling procedure.

The loading scheme was identical for each specimen and each loading direction. The speed of load was equal to $8.4 \mathrm{~mm} / \mathrm{min}$, which corresponds to a macroscopic strain rate equal to $2 \cdot 10^{-3} \mathrm{~s}^{-1}$. Each specimen was initially preloaded up to $5 \mathrm{~N}$ in order to establish contact between specimen and compression plates. After four loading cycles in series with $\Delta \mathrm{d}=15 \mathrm{~mm}(21.5 \%$ of macroscopic strain from the initial state), the fifth cycle with $\Delta \mathrm{d}=10 \mathrm{~mm}$ ( $14.3 \%$ of macroscopic strain from the initial state) was applied. Displacement load was always applied relative to the starting point of the following cycle. Pre-cycling eliminates effects of permanent (broken or/and shifted links) and temporary (Mullin's effect) damage in the material. Experimental data from the 5th cycle was used in the following study.

Pre-cycling effect (residual strain) was not the same for all the specimens. Thus, for a better correspondence between experimental data obtained for different specimens and loading directions, experimental curves were plotted in Force vs macroscopic strain coordinates. The experimental procedure was performed in each of three main directions $(\mathrm{Z}, \mathrm{Y}$ and $\mathrm{X})$ with $2 \mathrm{~h}$ rest time in the climate chamber between experiments.

\subsubsection{Global response (experimental study)}

Values of parameters $F_{\max }$ and $E_{\%}$ in each of three main loading directions are summarized in Table 2. It was found that a relative frictional sliding between specimen and compression plates leads to an additional energy dissipation (see values of $E_{\%}$ for the V00D10 specimen without inclusions). The value of $E_{\%}$ connected to this friction will be referred by $E_{\%}^{f r}$ in the following text.

Assuming that the value of $E_{\%}^{f r}$ remains constant for all the specimens considered, it can be found that $E_{\%}^{f r}$ constitutes a significant part of $E_{\%}$ for studied specimens (from $11 \%$ up to $36 \%$ for X- and Yload directions and up to $70 \%$ for the Z-load direction).
From Table 2 it can be seen that, for almost all VM specimens, Zloading direction is characterized by a decreased value of $F_{\max }$ and increased value of $E_{\%}$ compared to other loading directions. For example, for the specimen V15-D10, $F_{\max }^{Z}=414 \mathrm{~N}$, while $F_{\max }^{X}$ and $F_{\max }^{Y}$ are equal to 430 and $436 \mathrm{~N}$ respectively. The value of $E_{\%}$ for the same specimen is about $13 \%$ higher in Z-loading direction. These differences can be explained by recalling silicone molding process and the fact that the molding box was filled with the silicone in the Z-direction. Due to the surface tension a concave meniscus-like effect can be observed. Consequently, after drying, the top surface in the Z-direction of the specimen has a small curvature, which changes contact conditions during the experiment. We believe that this difference in the contact conditions at different loading directions led to the difference in the observed mechanical behavior. It must be noted that contribution of this concave meniscus cannot be estimated and, as a result, the comparison between $\mathrm{Z}$ and $\mathrm{X}$ or $\mathrm{Z}$ and $\mathrm{Y}$ directions becomes difficult. Comparison between data obtained in $\mathrm{X}$ and $\mathrm{Y}$ directions for a given specimen, on the contrary, have not shown significant anisotropy. Thus, for the sake of simplicity, experimental results corresponding to the Y-loading direction were considered here.

\subsection{Finite element approach}

\subsubsection{Material models}

Inclusions were modelled using Hooke's law for elastic materials with parameters taken in accordance with ABS material specifications $(E=2150 \mathrm{MPa}$ and $v=0.4)$. The nonlinear elastic behavior of the silicone matrix was modelled using the Arruda-Boyce hyperelastic model as it provides good prediction capabilities along with a stable behavior [31].

Inverse identification method was implemented to determine parameters of the hyperelastic material model with an increased accuracy. This method was based on minimization of a mean square difference between Force vs Displacement curves obtained for V00-D10 specimen during the experimental study and FE simulation. An iterative algorithm was developed using Python programming language to control optimization process. 
Table 2

Maximum force and dissipated energy fraction data obtained during experimental investigation of VM specimens subjected to compression load.

\begin{tabular}{|c|c|c|c|c|c|c|}
\hline & $F_{\max }[\mathrm{N}]$ & & & $E_{\%}[\%]$ & & \\
\hline Specimen & $\mathrm{X}$ & $\mathrm{Y}$ & Z & $\mathrm{X}$ & $\mathrm{Y}$ & Z \\
\hline V00-D10 & 398 & 400 & 372 & $E_{\%}^{f r}=2.2$ & $E_{\%}^{f r}=1.8$ & $E_{\%}^{f r}=5.2$ \\
\hline V7.5-D8 & 427 & 428 & 401 & 6.6 & 6.5 & 7.8 \\
\hline V7.5-D12 & 394 & 393 & 379 & 6.0 & 6.3 & 7.2 \\
\hline V15-D10 & 430 & 436 & 414 & 8.3 & 8.2 & 9.3 \\
\hline V22.5-D8 & 396 & 378 & 388 & 12.4 & 10.9 & 11.4 \\
\hline V22.5-D12 & 397 & 406 & 406 & 12.1 & 11.0 & 12.6 \\
\hline V30-D10 & 480 & 490 & 476 & 15.6 & 15.7 & 16.5 \\
\hline
\end{tabular}

Constants of the material model were modified in each iteration step and a new simulation was performed afterwards. In this way, inverse identification method allows fitting of the material model using the mechanical response of the material subjected to a multiaxial state of load (due to the geometry of the specimen and applied boundary conditions). Constant set identified by the inverse-identification fitting algorithm (coefficient of determination $R^{2}=0.99$ ) is presented in Table 3 .

\subsubsection{Finite element model of VM specimens}

a) Meshing

The complex geometry of VM specimens requires additional attention during meshing process. A big difference between macroscopic and local characteristic sizes of a specimen makes complicated the choice of meshing method and an element size (i.e. an edge of the cubic specimen $L+\Delta L=70 \mathrm{~mm}$ is much higher than the minimum distance between inclusions $a=1 \mathrm{~mm}$ ). An example of obtained mesh for the matrix and inclusions is presented in Fig. 5a and b.

\section{b) Boundary conditions}

For reasons of simplification and reduction of computational time, displacement boundary conditions were applied directly on the top surface of the structure (Fig. $5 c$ ). Nodes on the top surface were rigidly coupled together and fixed in al DOFs except for the direction of loading. Nodes on the bottom surface were also coupled and all DOFs were fully constrained. These boundary conditions allow to greatly reduce the complexity of the numerical problem by eliminating resolution of the contact problem between specimen and compression plates. This corresponds to a "glued" top and bottom surfaces of a specimen, which can be accepted as an approximation of a real case.

\section{c) Contact type influence; influence of the friction value}

Modeling of the VM structure requires the definition of a contact law between the matrix and inclusions. In general, this contact must be defined either as a tie constraint contact (an effect of inclusions "glued" to the matrix) or as a frictional contact (relative displacements and disconnection of contact surfaces are allowed).

Table 3

Constants of Arruda-Boyce hyperelastic model.

\begin{tabular}{llc}
\hline Arruda-Boyce hyperelastic model & \multicolumn{2}{l}{ Constants of the model } \\
\hline$W_{A B}=C_{1} \sum_{i=1}^{5} \alpha_{i} \beta^{i-1}\left(I_{B}{ }^{i}-3^{i}\right)$ & $C_{1}[\mathrm{MPa}]$ & $N$ \\
\hline with $\beta=\frac{1}{N} ; \alpha=\left[\frac{1}{2}, \frac{1}{20}, \frac{11}{1050}, \frac{19}{7000}, \frac{519}{673750}\right]$ & 0.132 & 6.549 \\
\hline
\end{tabular}

$I_{B}$ is the first invariant of the left Cauchy-Green deformation tensor.

$W_{A B}$ is the strain energy function of the Arruda-Boyce hyperelastic model.
It was found during the experimental investigation that VM specimens dissipate energy during cyclic loading, while silicone material of the matrix exhibits a hyperelastic behavior and does not dissipate energy by itself. Thus, energy dissipation during cyclic loading was caused by friction between inclusions and the matrix and the frictional contact type was chosen.

In order to find an appropriate value of friction coefficient, preliminary simulations were carried out. Influence of the value of friction coefficient on the mechanical behavior of the structure was studied using V15-D10 specimen. This specimen was chosen as a compromise between complexity of the numerical model and the number of inclusions in the structure. Force vs Deformation curves obtained during compression experiment and FE simulation using different friction coefficients are presented in Fig. 6.

It can be seen that a decrease in the value of friction coefficient leads to a decrease in the value of $F_{\max }$. The value of friction coefficient equal to 0.1 provides the best fit to experimental data. However, the lower the friction coefficient, the higher relative displacements between contacting surfaces and the higher the numerical complexity of the finite element problem. For example, a decrease of a friction coefficient from 0.3 to 0.1 increases the computational time by $40 \%$ (from $\sim 19.5 \mathrm{~h}$ to $\sim 48 \mathrm{~h}$ ). Thus, following the compromise between accuracy and computational efficiency, a friction coefficient value equal to 0.3 was chosen for $\mathrm{FE}$ simulation.

\subsubsection{Global response (FE study)}

Summary of all macroscopic data $\left(F_{\max }\right.$ and $\left.E_{\%}[\%]\right)$ obtained during FE simulation campaign is summarized in Table 4.

First simulation results, obtained for specimens V7.5-D8, V7.5D12 and V15-D10 in all three directions of load (X, Y and Z) and for the specimen V22.5-D8 (with the highest number of inclusions) in two load directions ( $\mathrm{Y}$ and $\mathrm{Z}$ ), have shown that observed anisotropy of the specimen's behavior does not exceed $0.5 \%$ of the value of $F_{\max }$ and $5.5 \%$ of the value of $E_{\%}$ and can be neglected (Table 4 ). Thus, only Y-direction of loading was considered for the further study.

\subsection{Comparison between two approaches}

\subsubsection{Comparison of the global responses}

Comparison between the global response of numerical and real VM specimens was carried out in terms of coefficient of determination $R^{2}$, parameter of the material stiffness $F_{\max }$ and dissipative capabilities parameter $E_{\%}$ (Fig. 7a). Additionally, comparison of Force vs Macroscopic strain curves was carried out. For example, Fig. 7b shows that the numerical model successfully predicts the global mechanical behavior of V15-D10 and V30-D10 specimens. It can be noted that the relative difference between values of $F_{\max }$ for specimens V00-D10, V7.5-D8, V15-D10 and V30-D10 calculated using experimental and FE simulation data is small and varies from 0 to $5 \%$. 
(a)

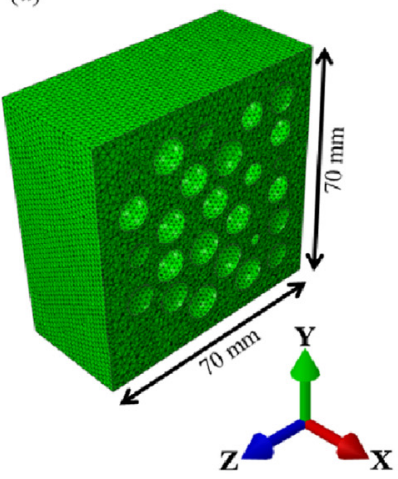

(b)

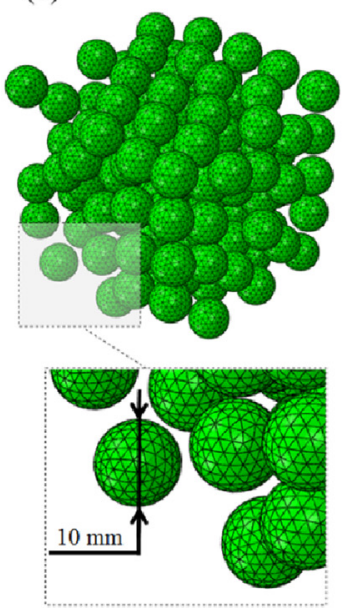

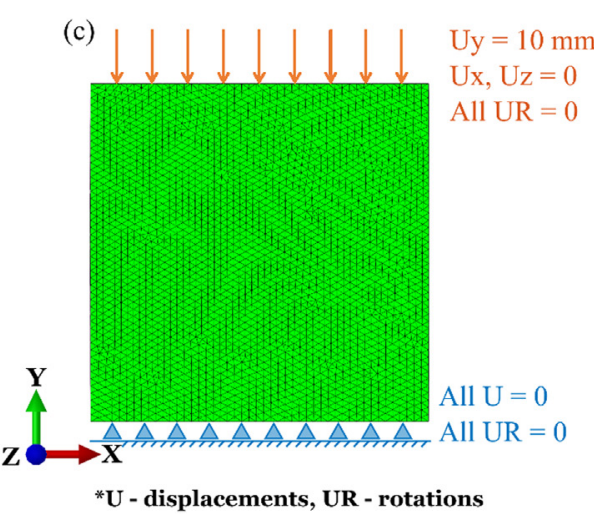

${ }^{*} \mathrm{U}$ - displacements, UR - rotations

Fig. 5. The mesh of the matrix (a) and (b) inclusions the V30-D10 specimen; (c) boundary conditions for VM finite element model.

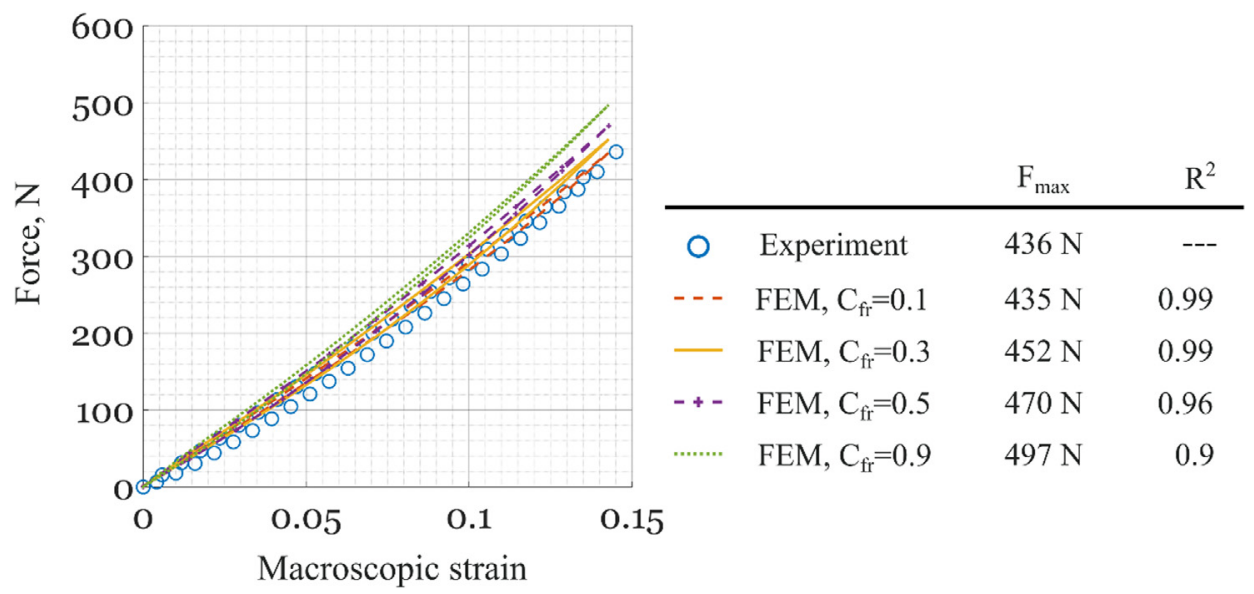

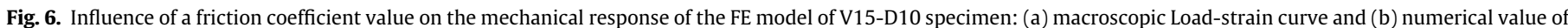
$F_{\max }$ and coefficient of determination value.

Table 4

Maximum force and dissipated energy fraction data obtained during FE simulation of VM specimens subjected to compression load.

\begin{tabular}{|c|c|c|c|c|c|c|}
\hline \multirow[b]{2}{*}{ Specimen } & \multicolumn{3}{|c|}{$F_{\max }[\mathrm{N}]$} & \multicolumn{3}{|c|}{$E_{\%[}[\%]$} \\
\hline & $\mathrm{X}$ & $\mathrm{Y}$ & $\mathrm{Z}$ & $\mathrm{X}$ & $\mathrm{Y}$ & Z \\
\hline V00-D10 & - & 399.6 & - & - & 0.0 & - \\
\hline V7.5-D8 & 426.6 & 426.2 & 425.8 & 2.4 & 2.4 & 2.2 \\
\hline V7.5-D12 & 428.2 & 427.6 & 428.5 & 2.3 & 2.4 & 2.4 \\
\hline V15-D10 & 451.1 & 452.5 & 450.5 & 4.7 & 4.8 & 4.6 \\
\hline V22.5-D8 & - & 475.6 & 475.9 & - & 7.3 & - \\
\hline V22.5-D12 & - & 480.1 & - & - & 7.5 & - \\
\hline V30-D10 & - & 515.9 & - & - & 10.3 & - \\
\hline
\end{tabular}

Obviously, due to established boundary conditions and chosen material behavior, FE model of the V00-D10 specimen does not show any energy dissipation $\left(E_{\%}^{F E M}=0 \%\right)$. On the opposite, the presence of friction between the specimen and compression plates results in energy dissipation during the experimental study $\left(E_{\%}^{\exp }=E_{\%}^{f r}=1.8 \%\right.$ ). Thus, for comparison, the value of $E_{\%}^{\text {exp }}$ for all specimens was decreased by $E_{\%}^{f r}$ (see histogram for $E_{-} \%$ in Fig. 7a). We must note that in this case, the difference $E_{\%}^{e x p}-E_{\%}^{F E M}$ lays in between 1.6 and $2.3 \%$ for most of the specimens and may be explained by the frictional dissipation on rigid links.

\subsubsection{Response surfaces}

The Doehlert experimental design uses a second-degree polynomial model to predict response value and construct the "response surface" [26]:

$y_{\text {mod }}\left(\widehat{V}_{f r}, \widehat{D}\right)=b_{0}+b_{1} \widehat{V}_{f r}+b_{2} \widehat{D}+b_{3} \widehat{V}_{f r} \widehat{D}+b_{4} \widehat{V}_{f r}^{2}+b_{5} \widehat{D}^{2}$

where $\widehat{V}_{f r}$ and $\widehat{D}$ are standardized variables of $V_{f r}$ and $D$ respectively and $b_{i}(i=0, \ldots 5)$ are parameters of the model. Identification of parameters $b_{i}$ is carried out as a linear least square minimization of the error between results of 7 experiments and the model 
(a)
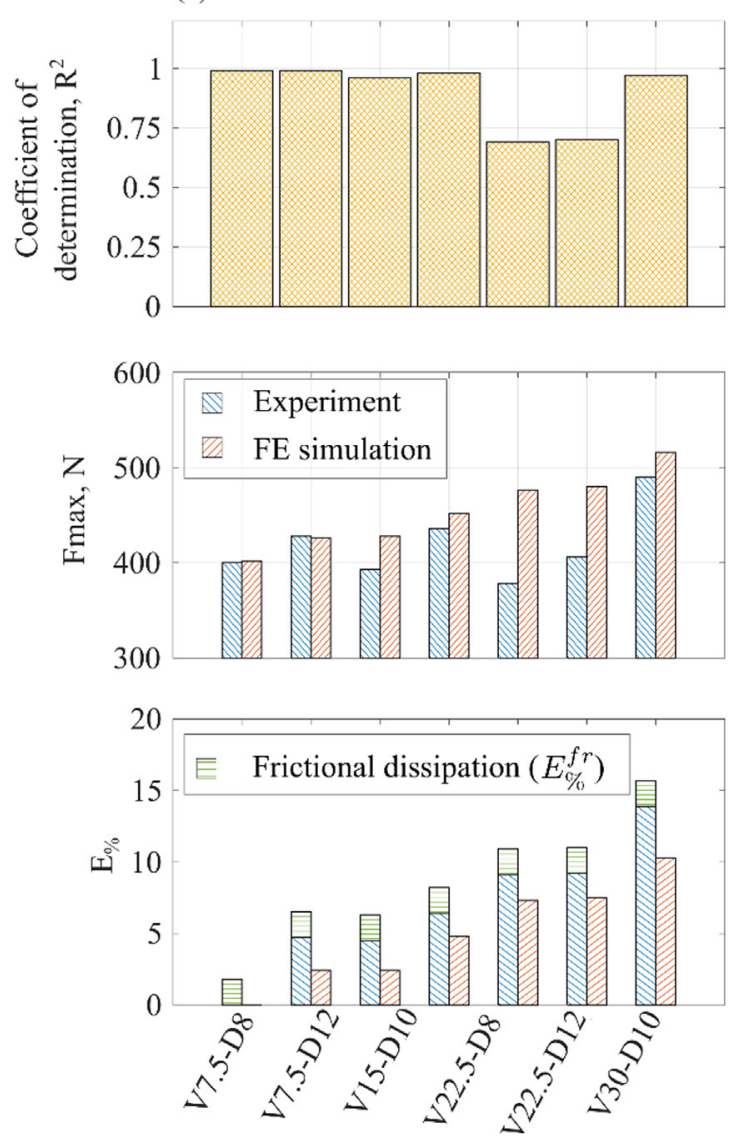

(b)
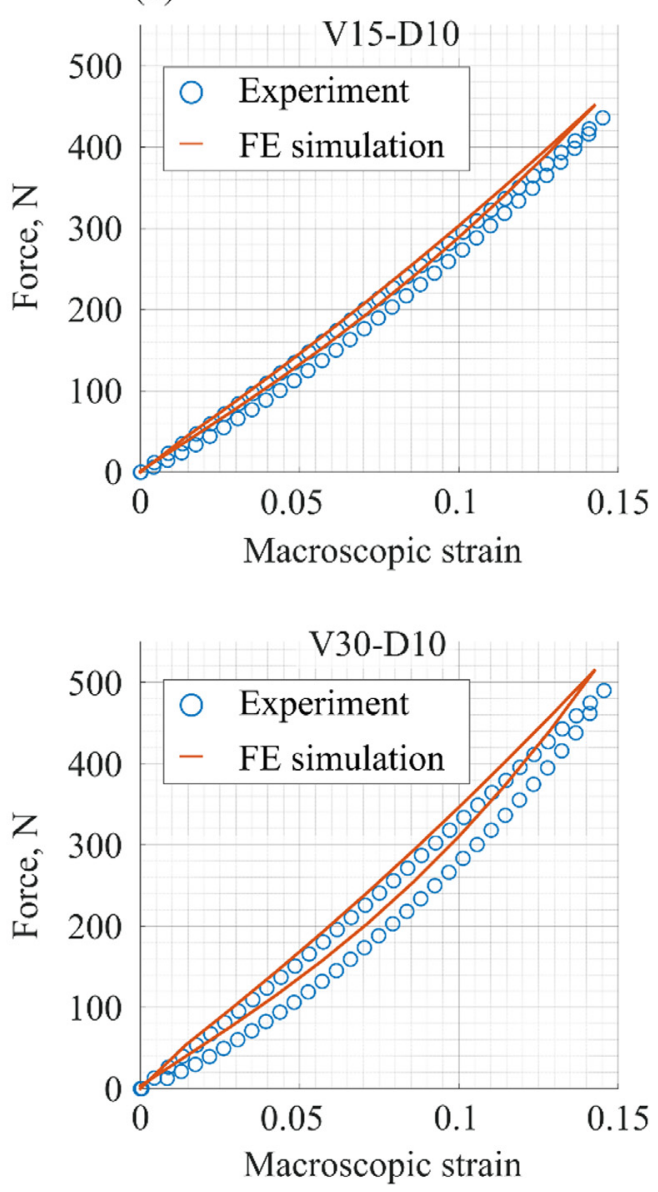

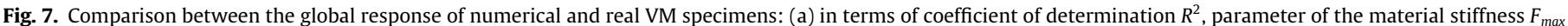
and dissipative capabilities parameter $E_{\%}$; (b) by whole Force vs Macroscopic strain curves (for V15-D10 and V30-D10 specimens).

response with the help of the Moore-Penrose pseudoinverse matrix [32]:

$\boldsymbol{b}=\left(\boldsymbol{Z}^{T} \boldsymbol{Z}\right)^{-1} \boldsymbol{Z}^{T} \boldsymbol{y}$

where $\boldsymbol{b}$ is a column vector of unknown parameters of the model, $\boldsymbol{Z}$ is the $7 \times 6$ matrix of the model and $\boldsymbol{y}$ is a column vector of 7 experimental measurements.

Identification of the most significant input factors (among $V_{f r}$ and $D$ ), as well as a qualitative study of variation of the response variable $\left(F_{\max }\right.$ or $\left.E_{\%}\right)$ with an increased precision was carried out using response surface method.

a) maximum force parameter

Response surfaces for the $F_{\max }$ parameter obtained using experimental and numerical data are presented in Fig. 8 and their expressions are as follows:

$$
\begin{aligned}
F_{\max }^{\operatorname{Exp}}\left(\widehat{V}_{f r}, \widehat{D}\right)= & 436.18+23.82 \widehat{V}_{f r}-1.79 \widehat{D}+36.44 \widehat{V}_{f r} \widehat{D} \\
& +8.57 \widehat{V}_{f r}^{2}-49.3 \widehat{D}^{2} \\
F_{\max }^{F E M}\left(\widehat{V}_{f r}, \widehat{D}\right)= & 452.49+54.96 \widehat{V}_{f r}+1.71 \widehat{D}+1.77 \widehat{V}_{f r} \widehat{D} \\
& +6.4 \widehat{V}_{f r}^{2}-2.32 \widehat{D}^{2}
\end{aligned}
$$

Fig. 8 shows that, in the experimental case, $F_{\max }$ varies nonmonotonically with the growth of input parameters $V_{f r}$ and $D$. Moreover, a maximum value of $F_{\max }$ can be found at each value of $V_{f r}$.
On the opposite, $F_{\max }$ parameter of numerical specimens grows monotonically with an increase in the value of $V_{f r}$ and has a negligible dependency on the value of $D$ : in Eq. (4b), coefficients of $V_{f r}$ parameter are always higher than the corresponding coefficients of $D$ parameter.

b) Energy parameter

Response surfaces for the $E_{\%}$ parameter obtained using experimental and numerical data are presented in Fig. 9 and their expressions are as follows (the value of $E_{\%}^{f r}$ was not subtracted from experimental data):

$$
\begin{aligned}
E_{\%}^{E x p}\left(\widehat{V}_{f r}, \widehat{D}\right)= & 8.18+6.15 \widehat{V}_{f r}-0.035 \widehat{D}+0.208 \widehat{V}_{f r} \widehat{D} \\
& +0.53 \widehat{V}_{f r}^{2}+0.483 \widehat{D}^{2} \\
E_{\%}^{F E M}\left(\widehat{V}_{f r}, \widehat{D}\right)= & 4.772+5.107 \widehat{V}_{f r}+0.088 \widehat{D}+0.092 \widehat{V}_{f r} \widehat{D} \\
& +0.398 \widehat{V}_{f r}^{2}+0.015 \widehat{D}^{2}
\end{aligned}
$$

It is seen that in both experimental and numerical cases the capability of VM to dissipate energy grows monotonically with an increase in the value of $V_{f r}$. A negligible dependency of $E_{\%}$ on the value of $D$ has been found during both approaches: it can be seen in Eq. ( $5 a$ and b) that coefficients of size parameter are smaller than the corresponding coefficients of volume fraction parameter. 

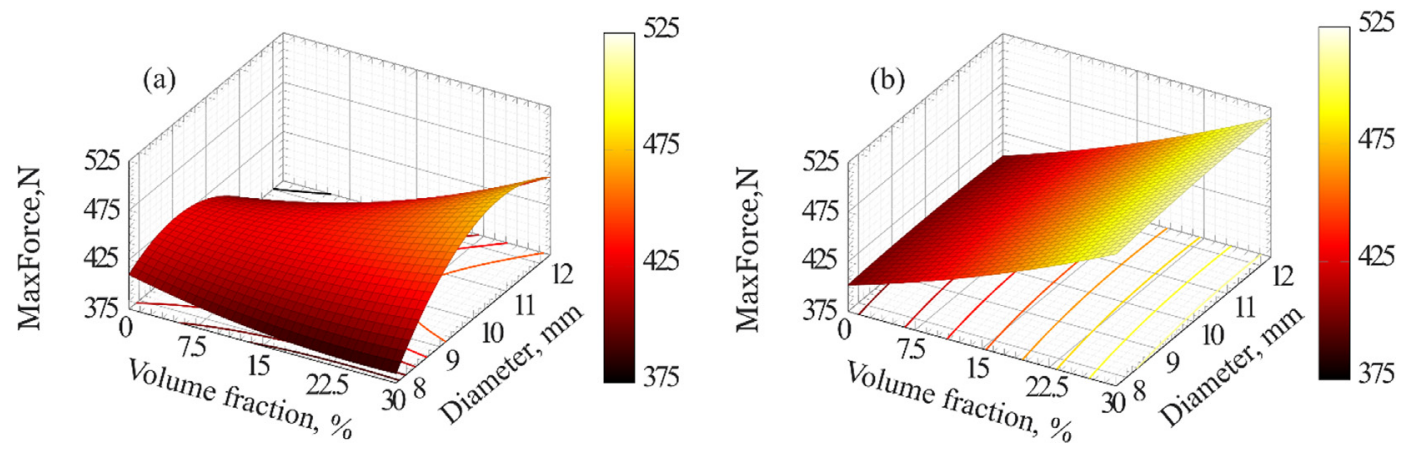

Fig. 8. $F_{\max }$ parameter of VM stiffness obtained during (a) experimental and (b) numerical studies as a function of inclusions' volume fraction and diameter.

It can be concluded from Eq. (5a and b) that during experimental study the value of $D$ has a higher influence on the value of $E_{\%}$ than during numerical simulation.

\subsection{Discussion of experimental and numerical results}

Possible sources of the observed differences between the macroscopic response of real and numerical specimens can be discussed. First of all, despite the small volume fraction and absence of a primary orientation of rigid links (see Section 2.3.3b), their presence (see Fig. 10a) can, though, influence the overall behavior of specimens. Secondly, modeling of voids nucleation in the regions of inclusions-matrix separation (no adhesion between matrix and inclusions, Fig. 10b) can be not accurate enough because of the complex stair-like surface of real inclusions manufactured using 3D printing (Fig. 10c). Finally, additional energy dissipation observed during the experimental investigation can be connected with this stair-like surface of links and inclusions, while its influence may be non-uniform and may depend on the relative location of inclusions and the level of applied load.

Taking into account presented approximations and differences, it can be concluded that FE model establishes a satisfactory prediction of a global behavior of real specimens. Thus, numerical specimens can be used to study the internal mechanics of VM.

\section{Analysis of VM at meso-scale}

\subsection{Load-bearing chains (surface of projections method)}

In powders/granular materials the external axial load is nonhomogeneously transmitted through contacts between particles, forming load-bearing chains (or force networks) which are going through the material in the direction of load [33]. A similar mechanism can be assumed for a soft matrix reinforced by rigid particles. Schematically, this type of load transmission is presented in Fig. 11a: closely located inclusions form regions of stress concen-

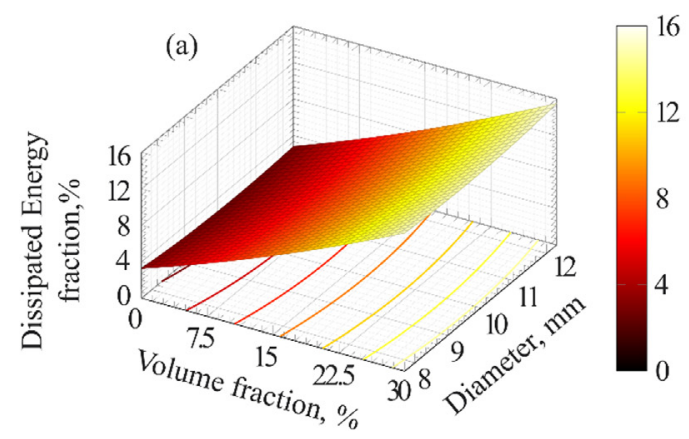

trations, which support most of the external load. Thus, the strength of a composite material is not homogeneously distributed throughout its structure.

Analysis of potential load-bearing chains was performed using "surfaces of projections", constructed by projecting inclusions on one of the 3 main planes of the cube. At each point, the magnitude of such surface is defined by the number of inclusions projected to this point (Fig. 11b). Construction of such surfaces for three main planes of the cube (XY, XZ and YZ) allows to study length and density of potential load-bearing chains and, in this way, compare rigidity of each specimen in different directions on a theoretical basis. Surfaces of projections were built with a resolution of $0.25 \mathrm{~mm}$ (Fig. 11b).

Fig. 12 represents the surface of projections for the V22.5-D8 specimen with the highest number of inclusions (surfaces of projections for the rest of specimens can be found in Appendix). The region with a given number of projected inclusions will be referred by variable $n: n=1$ for at least one projected inclusion, $n=2$ for at least two projected inclusions, etc. The maximum magnitude will be denoted by $n_{\max }$.

Although it is impossible to define the number of load-bearing chains from the present analysis, it must be proportional to the total area covered by each of $n$ colour contours. Fraction $S_{f r}^{n}$ of a $60 \times 60$ square surface area covered by each of $n$ colour contours can be calculated for each of three main directions to confirm conclusions about specimens' isotropy and perform the comparison between specimens.

Additionally, the variation of the value $S_{f r}^{n}$ calculated for different directions was analyzed using variation coefficient $C_{v a r}$, defined as follows:

$C_{\text {var }}=\frac{1}{\mu} \sqrt{\frac{\left(S_{f r}^{n}(X)-\mu\right)^{2}+\left(S_{f r}^{n}(Y)-\mu\right)^{2}+\left(S_{f r}^{n}(Z)-\mu\right)^{2}}{3}}$

where $\mu=\frac{1}{3}\left[S_{f r}^{n}(X)+S_{f r}^{n}(Y)+S_{f r}^{n}(Z)\right]$ is the mean value of $S_{f r}^{n}$ for a given $\mathrm{n}$. The value of $S_{f r}^{n}$ calculated for the contour with number

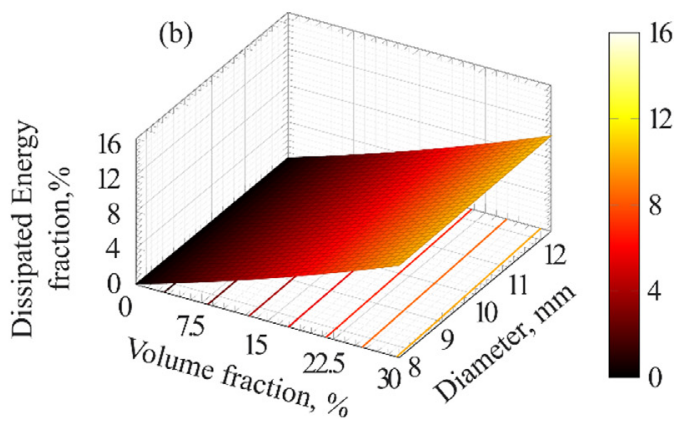

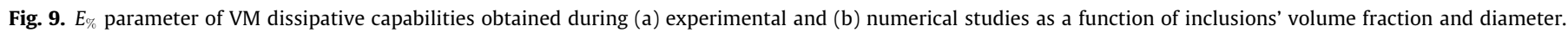


(a) Undeformed

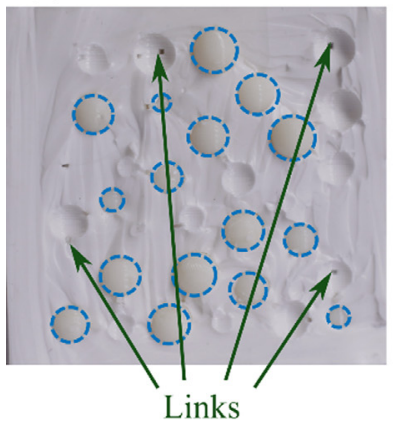

(b)

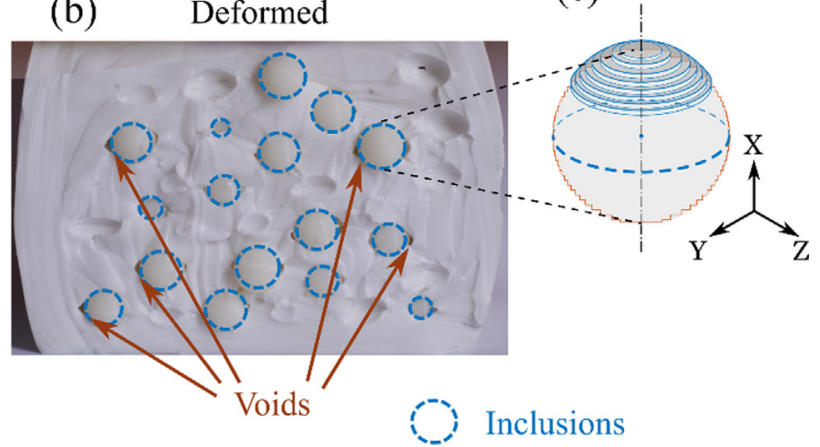

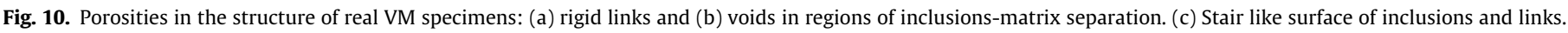

$n=n_{\max }$ will be denoted in the following text as $S_{f r}^{\max }$. Obtained data are presented in Table $5 \mathrm{a}-\mathrm{c}$.

First of all, it is seen that an increase in the volume fraction, as well as a decrease in the size of inclusions, lead to an increase in load-bearing chains density (an increase in $S_{f r}^{n}$ for each $n$ ) and an increase in $n_{\max }$.

Differences between main directions of specimens can be found comparing data presented in Fig. 12 and Table 5a-c. For example, the value of $n_{\max }$ obtained for the V22.5-D12 specimen in the Ydirection (XZ-plane) is equal to 5 , while, for the other two directions, this value is equal to 4 . It means that potentially $Y$ direction of the specimen can have a higher rigidity. Similarly, for the case of the V7.5-D12 specimen, $n_{\max }$ equals to 2 in the Xdirection and to 3 in the other directions. It is also seen that the value of $C_{v a r}$ grows with an increase of contour number $n$. It means that the difference between values of $S_{f r}^{n}$, calculated for X-, Y- and $Z$ - directions becomes more distinct for high values of $n$, and, thereby, it can be assumed that the stiffest direction can be found by the highest value of $S_{f r}^{\max }$ (e.g. X for V7.5-D8, Y for V22.5-D8, Z for V22.5-D12, etc.). A relatively small values of $S_{f r}^{\max }$, however, allow to consider these differences in stiffness as negligible. The last conclusion can be indirectly confirmed by experimental and numerical results discussed in Section 3 (see Table 2 and Table 4).

\subsection{Local stress-strain concentrations (FE method)}

Stress/strain concentrations localized in the matrix material, confined between inclusions, can be presented by taking crosssections of the FE model of a studied specimen. Stress-strain maps obtained in such cross-sections allow to visualize load-bearing (a)

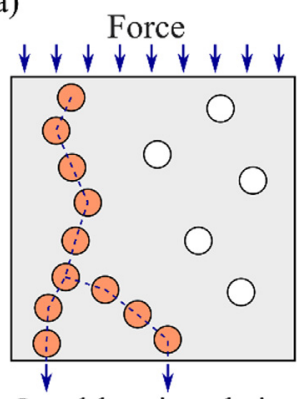

(b)

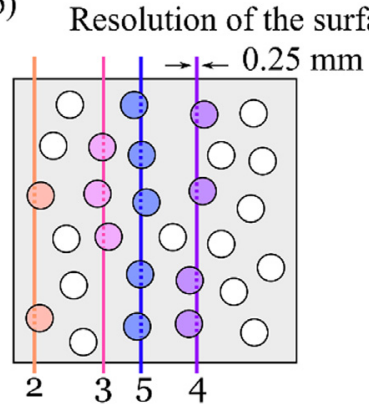

Fig. 11. (a) Schematic representation of a load-bearing chain in a composite material; (b) construction of a surface of projections. chains defined previously. It was assumed that the longest loadbearing chains correspond to regions of highest stress-strain concentrations. Thus, a position for the cross section was chosen in accordance with the location of potential load-bearing chains determined by projection surfaces.

An example of such analysis, carried out for the V22.5-D8 specimen, is presented in Fig. 13. A similar approach can be used for the rest of the specimens. Maps of Von Mises stress and Y-component of the true strain tensor were calculated at a $\times=5 \mathrm{~mm}$ cross section and are presented in Fig. 13a and b. Inclusions' geometries were removed from figures for a better representation of the stress-strain state in the matrix.

Von Mises stress, computed from components of the Cauchy stress tensor, can be considered as an integral parameter of a material stress state. In this way, a map of Von Mises stress values can represent stress concentrations regardless the prevailing loading type (uniaxial, shear, etc.). Chains of Von Mises stress concentrations going from the top to the bottom of the specimen are presented in Fig. 13a. As it was assumed earlier, it is seen that a higher number of inclusions in the section leads to an increase in a density and length of load-bearing chains. It can be also noted that the value of Von Mises stress in the present cross sections reaches $\sim 0.56 \mathrm{MPa}$, while the average value in the matrix is about $0.045 \mathrm{MPa}$ ( 12.5 times lower).

The similar picture can be found for the Y-true strain map: distinct chains of strain concentrations can be found in the present section (Fig. 13b). It can be found that the magnitude of strain reaches values 3-5 times higher than the average in the matrix and 5-7 times higher than the applied strain ( $10 \mathrm{~mm}$ of applied load $\sim 0.15$ of true strain).

\section{Conclusions}

Influence of heterogeneities (size and volume fraction of monodisperse spherical inclusions) on the mechanical response of composite structure was investigated using new "Virtual Material" approach, which keeps the connection between numerical and real cases of study. Results have shown a significant dependence of the global response on the value of $V_{f r}$ and non-significant dependence on the value of $D$.

The VM approach can be used in tasks of homogenization as well as localization of stress/strain concentrations and numerical optimization of the internal structure of the material.

Improvement of the studied case in terms of problem discretization (polydisperse and/or polyhedral shape inclusions) and constitutive materials (visco-hyperelastic matrix, materials with mutual adhesion, etc) can be proposed in order to study a more general problem. 


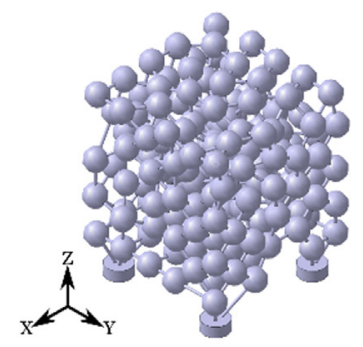

Number of projected inclusions, $n$
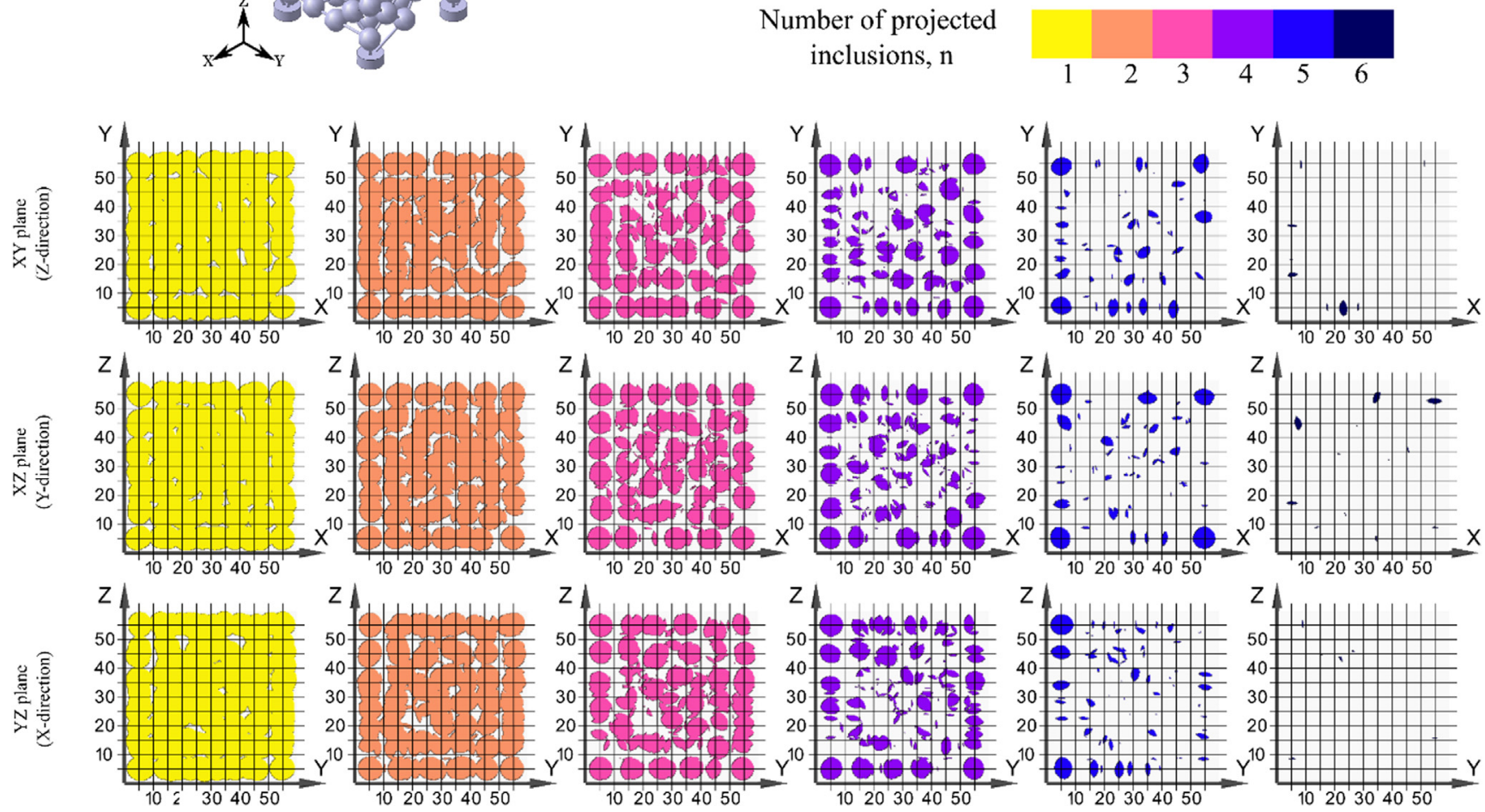

Fig. 12. Surfaces of projections for the specimen V22.5-D8.

Table 5a

$S_{f r}^{n}[\%]$ calculated for each of the main directions and for different $n$ - specimens V7.5-D8 and V7.5D12.

\begin{tabular}{|c|c|c|c|c|c|c|c|c|c|}
\hline & \multicolumn{4}{|c|}{ V7.5-D8 } & \multicolumn{5}{|c|}{ V7.5-D12 } \\
\hline & $S_{f r}^{n}(X)$ & $S_{f r}^{n}(Y)$ & $S_{f r}^{n}(Z)$ & $C_{v a r}[\%]$ & $S_{f r}^{n}(X)$ & $S_{f r}^{n}(Y)$ & $S_{f r}^{n}(Z)$ & $C_{\text {var }}[\%]$ & \\
\hline \multirow{5}{*}{ Number of projected inclusions $(n)$} & 1 & 47.53 & 52.03 & 54.58 & 5.7 & 46.8 & 45.18 & 39.49 & 7.2 \\
\hline & 2 & 22.78 & 22.32 & 21.07 & 3.3 & 9.71 & 9.76 & 14.86 & 21.1 \\
\hline & 4 & 2.48 & 1.13 & 0.02 & 83.4 & 0.0 & 0.0 & 0.0 & - \\
\hline & 5 & 0.0 & 0.0 & 0.0 & - & 0.0 & 0.0 & 0.0 & - \\
\hline & 6 & 0.0 & 0.0 & 0.0 & - & 0.0 & 0.0 & 0.0 & - \\
\hline
\end{tabular}

Table 5b

$S_{f r}^{n}[\%]$ calculated for each of the main directions and for different $n$ - specimens V22.5-D8 and V7.5D12.

\begin{tabular}{|c|c|c|c|c|c|c|c|c|c|}
\hline & \multicolumn{4}{|c|}{ V22.5-D8 } & \multicolumn{5}{|c|}{ V22.5-D12 } \\
\hline & $S_{f r}^{n}(X)$ & $S_{f r}^{n}(Y)$ & $S_{f r}^{n}(Z)$ & $C_{v a r}[\%]$ & $S_{f r}^{n}(X)$ & $S_{f r}^{n}(Y)$ & $S_{f r}^{n}(Z)$ & $C_{\text {var }}[\%]$ & \\
\hline \multirow[t]{6}{*}{ Number of projected inclusions $(n)$} & 1 & 88.87 & 88.39 & 87.69 & 0.6 & 85.30 & 84.49 & 82.16 & 1.6 \\
\hline & 2 & 74.58 & 74.90 & 74.57 & 0.2 & 60.01 & 57.85 & 57.38 & 2.0 \\
\hline & 3 & 53.53 & 53.15 & 54.49 & 1.1 & 21.86 & 24.67 & 25.72 & 6.8 \\
\hline & 4 & 28.11 & 26.92 & 27.22 & 1.9 & 2.41 & 2.56 & 4.39 & 28.9 \\
\hline & 5 & 7.43 & 8.58 & 8.15 & 5.9 & 0.00 & 0.05 & 0.00 & - \\
\hline & 6 & 0.10 & 0.75 & 0.55 & 57.9 & 0.00 & 0.00 & 0.00 & - \\
\hline
\end{tabular}


Table 5c

$S_{f r}^{n}[\%]$ calculated for each of the main directions and for different $n$ - specimens V15-D10 and V30D10.

\begin{tabular}{|c|c|c|c|c|c|c|c|c|c|}
\hline & & \multicolumn{4}{|c|}{ V15-D10 } & \multicolumn{4}{|c|}{ V30-D10 } \\
\hline & & $S_{f r}^{n}(X)$ & $S_{f r}^{n}(Y)$ & $S_{f r}^{n}(Z)$ & $C_{\text {var }}[\%]$ & $S_{f r}^{n}(X)$ & $S_{f r}^{n}(Y)$ & $S_{f r}^{n}(Z)$ & $C_{\text {var }}[\%]$ \\
\hline \multirow[t]{6}{*}{ Number of projected inclusions $(n)$} & 1 & 68.88 & 65.90 & 71.87 & 3.5 & 90.32 & 90.27 & 93.09 & 1.4 \\
\hline & 2 & 42.94 & 45.72 & 42.99 & 3.0 & 80.89 & 79.05 & 83.97 & 2.5 \\
\hline & 3 & 19.39 & 18.13 & 17.40 & 4.5 & 62.07 & 59.83 & 61.30 & 1.5 \\
\hline & 4 & 4.06 & 5.50 & 3.03 & 24.1 & 31.54 & 33.36 & 26.95 & 8.8 \\
\hline & 5 & 0.00 & 0.00 & 0.00 & 0.00 & 5.11 & 7.39 & 4.81 & 20.0 \\
\hline & 6 & 0.00 & 0.00 & 0.00 & 0.00 & 0.51 & 0.63 & 0.32 & 26.38 \\
\hline
\end{tabular}

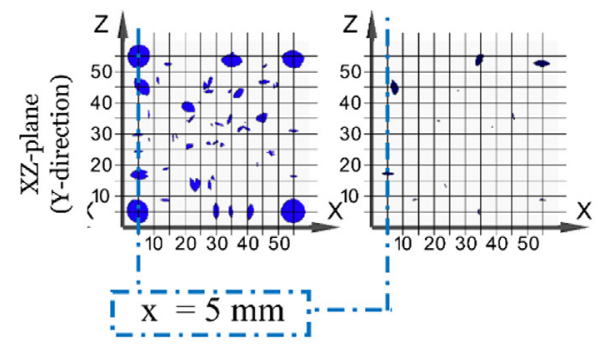

Number of projected inclusions, $\mathrm{n}$

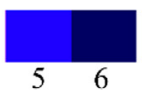

(a)

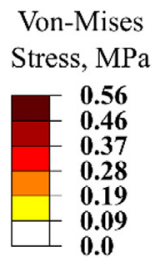

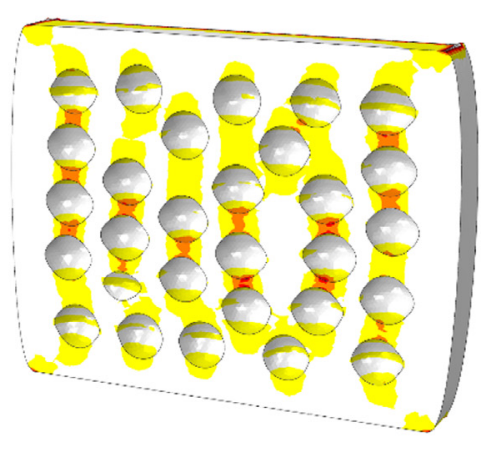

(b)

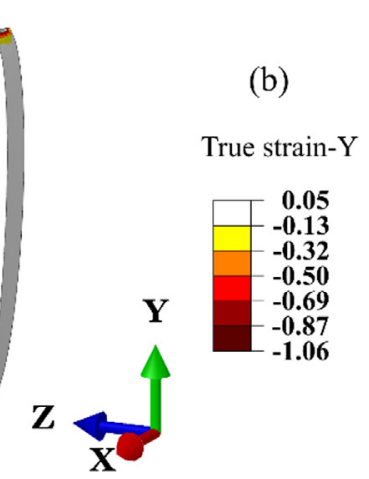

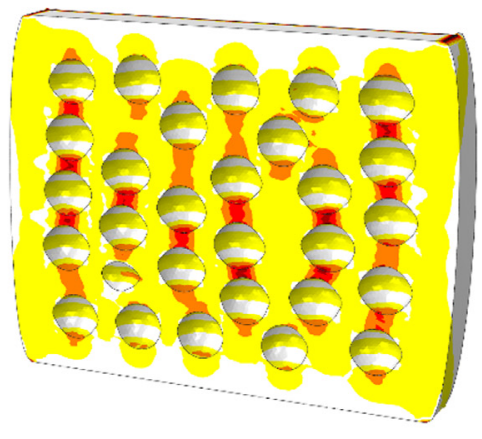

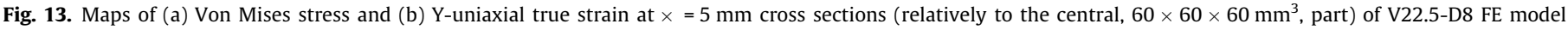
subjected to compression displacement of $10 \mathrm{~mm}$.

\section{Acknowledgment}

This research was carried out under the financial support of SNCF Railway Company. The authors would like to thank Pr. Philippe Viot for the helpful discussions regarding the subject of the present work.

\section{Appendix A. Supplementary data}

Supplementary data to this article can be found online at https://doi.org/10.1016/j.conbuildmat.2018.11.095.

\section{References}

[1] D.R. Cardona, H. Di Benedetto, C. Sauzéat, N. Calon, G. Saussine, Use of a bituminous mixture layer in high-speed line trackbeds, Constr. Build. Mater. 125 (2016) 398-407, https://doi.org/10.1016/j.conbuildmat.2016.07.118.

[2] National Academies of Sciences, A Manual for Design of Hot Mix Asphalt with Commentary, The National Academies Press, Washington, D.C., 2011.

[3] D. Mounier, H. Di Benedetto, C. Sauzéat, Determination of bituminous mixtures linear properties using ultrasonic wave propagation, Constr. Build. Mater. 36 (2012) 638-647, https://doi.org/10.1016/j.conbuildmat.2012.04.136.

[4] M. Pasetto, N. Baldo, Numerical visco-elastoplastic constitutive modelization of creep recovery tests on hot mix asphalt, J. Traffic Transp. Eng. (English Ed. 3 (2016) 390-397, https://doi.org/10.1016/j.jtte.2016.09.009.

[5] F. Olard, H. Di Benedetto, General "2S2P1D" model and relation between the linear viscoelastic behaviours of bituminous binders and mixes, Road Mater. Pav. Des. 4 (2003) 185-224, https://doi.org/10.1080/14680629.2003.9689946.

[6] Y. Ju, H. Xie, Z. Zheng, J. Lu, F. Gao, et R. Peng, Vizualization of the complex structure and stress field inside rock by means of 3D printing technology, Chin. Sci. Bull. 59 (2014) 5354-5365, https://doi.org/10.1007/s11434-014-0579-9.
[7] Q. Jiang, X. Feng, Y. Gong, L. Song, S. Ran, J. Cui, Reverse modelling of natural rock joints using 3D scanning and 3D printing, Comput. Geotechn. 73 (2016) 210-220, https://doi.org/10.1016/j.compgeo.2015.11.020.

[8] V. Ziaei-Rad, N. Nouri, S. Ziaei-Rad, M. Abtahi, A numerical study on mechanical performance of asphalt mixture using a meso-scale finite element model, Finite Elem. Anal. Des. 57 (2012) 81-91, https://doi.org/ 10.1016/j.finel.2012.03.004.

[9] L.T. Mo, M. Huurman, S.P. Wu, A.A.A. Molenaar, 2D and 3D meso-scale finite element models for ravelling analysis of porous asphalt concrete, Finite Elem. Anal. Des. 44 (2008) 186-196, https://doi.org/10.1016/j.finel.2007.11.012.

[10] A. Caballero, C.M. López, I. Carol, 3D meso-structural analysis of concrete specimens under uniaxial tension, Comput. Methods Appl. Mech. Eng. 195 (2006) 7182-7195, https://doi.org/10.1016/j.cma.2005.05.052.

[11] Y. Xu, S. Chen, A method for modeling the damage behavior of concrete with a three-phase mesostructure, Constr. Build. Mater. 102 (2016) 26-38, https:// doi.org/10.1016/j.conbuildmat.2015.10.151.

[12] J. Wimmer, B. Stier, J.W. Simon, S. Reese, Computational homogenisation from a 3D finite element model of asphalt concrete-linear elastic computations, Finite Elem. Anal. Des. 110 (2016) 43-57, https://doi.org/10.1016/j.finel.2015.10.005.

[13] P. Wriggers, S.O. Moftah, Mesoscale models for concrete: Homogenisation and damage behaviour, Finite Elem. Anal. Des. 42 (2006) 623-636, https://doi.org/ 10.1016/j.finel.2005.11.008.

[14] Z.Q. Yue, S. Chen, L.G. Tham, Finite element modeling of geomaterials using digital image processing, Comput. Geotech. 30 (2003) 375-397, https://doi. org/10.1016/S0266-352X(03)00015-6.

[15] Q. Dai, Z. You, Micromechanical finite element framework for predicting viscoelastic properties of asphalt mixtures, Mater. Struct. 41 (2007) 10251037, https://doi.org/10.1617/s11527-007-9303-4.

[16] T. You, R.K. Abu Al-Rub, M.K. Darabi, E.A. Masad, D.N. Little, Three-dimensional microstructural modeling of asphalt concrete using a unified viscoelasticviscoplastic-viscodamage model, Constr. Build. Mater. 28 (2012) 531-548, https://doi.org/10.1016/j.conbuildmat.2011.08.061.

[17] T. Schüler, R. Jänicke, H. Steeb, Nonlinear modeling and computational homogenization of asphalt concrete on the basis of XRCT scans, Constr. Build. Mater. 109 (2016) 96-108, https://doi.org/10.1016/ j.conbuildmat.2016.02.012. 
[18] Y. Huang, D. Yan, Z. Yang, G. Liu, 2D and 3D homogenization and fracture analysis of concrete based on in-situ X-ray computed tomography images and Monte Carlo simulations, Eng. Fract. Mech. 163 (2016) 37-54, https://doi.org/ 10.1016/j.engfracmech.2016.06.018.

[19] Y. Ju, L. Wang , H. Xie, G. Ma, L. Mao, Z Zheng J. Lu, Visualization of the threedimensional structure and stress field of aggregated concrete materials through 3D printing and frozen-stress techniques, Constr. Build. Mater. 143 (2017) 121-137, https://doi.org/10.1016/j.conbuildmat.2017.03.102.

[20] A. Trofimov, B. Drach, I. Sevostianov, Effective elastic properties of composites with particles of polyhedral shapes, Int. J. Solids Struct. 120 (2017) 157-170, https://doi.org/10.1016/j.ijsolstr.2017.04.037.

[21] S. Kari, H. Berger, R. Rodriguez-Ramos, U. Gabbert, Computational evaluation of effective material properties of composites reinforced by randomly distributed spherical particles, Compos. Struct. 77 (2007) 223-231, https:// doi.org/10.1016/j.compstruct.2005.07.003.

[22] Z. Guo, X. Shi, Y. Chen, H. Chen, X. Peng, P. Harrison, Mechanical modeling of incompressible particle-reinforced neo-Hookean composites based on numerical homogenization, Mech. Mater. 70 (2014) 1-17, https://doi.org/ 10.1016/j.mechmat.2013.11.004.

[23] A. El Moumen, T. Kanit, A. Imad, H. El Minor, Effect of reinforcement shape on physical properties and representative volume element of particles-reinforced composites: Statistical and numerical approaches, Mech. Mater. 83 (2015) 116, https://doi.org/10.1016/j.mechmat.2014.12.008.

[24] Z.F. Khisaeva, M. Ostoja-Starzewski, On the size of RVE in finite elasticity of random composites, J. Elast. 85 (2006) 153-173, https://doi.org/10.1007/ s10659-006-9076-y.
25] X.X. Zhang, B.L. Xiao, H. Andrä, Z.Y. Ma, Homogenization of the average thermoelastoplastic properties of particle reinforced metal matrix composites: the minimum representative volume element size, Compos. Struct. 113 (2014) 459468, https://doi.org/10.1016/j.compstruct.2014.03.048.

[26] D.H. Doehlert, V.L. Klee, Experimental designs through level reduction of the $\mathrm{d}$ dimensional cuboctahedron, Discrete Math. 2 (1972) 309-334, https://doi.org/ 10.1016/0012-365X(72)90011-8.

[27] S. Torquato, T.M. Truskett, P.G. Debenedetti, Is random close packing well defined?, Phys Rev. Lett. 84 (2000) 2064-2067.

[28] GranOO's wiki, (n.d.). http://www.lamef.bordeaux.ensam.fr/ granoo/ wiki/doku.php.

[29] P. Sheng, J. Zhang, Z. Ji, An advanced 3D modeling method for concrete-like particle-reinforced composites with high volume fraction of randomly distributed particles, Compos. Sci. Technol. 134 (2016) 26-35, https://doi. org/10.1016/j.compscitech.2016.08.009.

[30] J. Segurado, J. Llorca, A numerical approximation to the elastic properties of sphere-reinforced composites, J. Mech. Phys. Solids. 50 (2002) 2107-2121, https://doi.org/10.1016/S0022-5096(02)00021-2.

[31] P. Steinmann, M. Hossain, G. Possart, Hyperelastic models for rubber-like materials: consistent tangent operators and suitability for Treloar's data, Arch. Appl. Mech. 82 (2012) 1183-1217, https://doi.org/10.1007/s00419-012-0610-z.

[32] D.A. Harville, Matrix Algebra From a Statistician's Perspective, Springer, New York, 1997. doi: 10.1007/b98818.

[33] S.M.R. García-Rojo, H.J. Herrmann, Powders and Grains 2005, Two Volume Set: in: Proceedings of the International Conference on Powders \& Grains 2005 Stuttgart, Germany, 18-22 July 2005, n.d. 